Research Article

\title{
Predictors of African American Belief in Illness as Punishment for Sin
}

\author{
Emily Schulz \\ Northern Arizona University
}

Beverly Rosa Williams ${ }^{4}$

University of Alabama at Birmingham

\author{
R. Curtis Bay ${ }^{2}$ \\ A.T. Still University \\ Crystal Park $^{5}$ \\ University of Connecticut
}

\author{
Eddie M. Clark ${ }^{3}$ \\ Saint Louis University \\ Lijing $\mathrm{Ma}^{6}$ \\ Saint Louis University
}

Cheryl L. Knott $^{7}$

University of Maryland

${ }^{1}$ Emily Schulz, PhD, OTR/L, CFLE, ACUE, Northern Arizona University, Department of Occupational Therapy, Phoenix, Arizona, USA, email: Emily.Schulz@nau.edu

${ }^{2}$ A.T. Still University, Biostatistics, Mesa, Arizona, USA

${ }^{3}$ Saint Louis University, Department of Psychology, Saint Louis, Missouri, USA

${ }^{4}$ University of Alabama at Birmingham, Department of Sociology, Birmingham, Alabama, USA

${ }^{5}$ University of Connecticut, Department of Psychological Sciences, Storrs, Connecticut, USA

${ }^{6}$ Saint Louis University, Department of Psychology, Saint Louis, Missouri, USA

${ }^{7}$ University of Maryland, School of Public Health, College Park, Maryland, USA

Corresponding author: Emily Schulz

E-mail:

Emily.Schulz@nau.edu

eISSN: 2458-9675

Received: 10.05.2021

Revision: 21.09.2021

Accepted: 28.09.2021

CCopyright 2021

by Author(s)

\begin{abstract}
While religious participation is positively associated with health, and faith traditions often promote wholesome behavior among followers, religious beliefs endorsing the notion of illness as punishment for sin can be negatively related to health. To date, little is known about the correlates of this belief. This study examined demographic characteristics and religiosity as predictors of the belief that illness occurs as punishment for sin in a national probability sample of African American adults. Of 3,173 participants completing a telephone survey, 2,172 (68.45\%) moderately endorsed belief in illness as punishment for $\sin$ (mean of 16 [SD $=4.59]$ out of possible 32). Spearman correlations and linear regression modeling were conducted. Findings suggested that participants who were men, less educated, with lower income levels, lower religious beliefs, greater religious participation, greater use of negative religious coping, and both active and passive spiritual health locus of control beliefs, reported significantly stronger belief in illness as punishment for sin. Age, employment, and positive religious coping were not significant predictors. Psychologists, counselors, and health professionals working with African Americans may consider these findings in helping clients find healthy ways to reflect on their illnesses in collaboration with clergy, that are client-centered and respectful of their faith traditions.

Keywords:

Illness as punishment, African Americans, Religious coping, Spiritual health locus of control, Spiritual struggle, Religious beliefs, Religious behaviors
\end{abstract}


Approximately $89 \%$ of Americans believe in God (Newport, 2016), and this belief is more prevalent among African Americans than among individuals of other races or ethnicities (Masci, 2018). The religion-health connection has been studied extensively (Koenig, King, \& Carson, 2012; Ransome, 2020). On balance, these studies have found a positive relationship between religion and health. However, some research has been conducted on negative aspects of religious involvement such as negative religious coping (Holt, Clark \& Roth, 2014) and beliefs that illness may result from God's punishment for wrongdoing or sin (Holt et al, 2009).

Research suggests that people have illness schemas (Hagger \& Orbell, 2021), which are implicit or explicit beliefs about their illness, including its causes. These beliefs are acquired from family, friends, the media, and personal experiences and may influence a patient's decisions about seeking treatment. Religious and spiritual beliefs can affect the way people approach having an illness (Avent Harris, Wahesh, Barrow, \& Fripp, 2021). Illness schemas also can influence how individuals behave toward someone with an illness and may prejudice expectations about their future health (Anandarajah, Roseman, Mennillo, \& Kelley, 2021; Leventhal et al., 2008). If those providing healthcare believe that another's illness is caused by God's punishment for sin, the patient may be treated differently because the provider believes God was a causal agent (Anderson et al., 2010; Shiri, Mohtashami, Manoochehri, Nasiri, \& Rohani, 2020).

Belief in illness due to punishment for sin exists across cultures and religions and can be responsible for disapproving attitudes towards those with a health condition (Abulhul, 2020; Bhatnagar et al., 2017; Hulett et al., 2018; Lee et al., 2017). This phenomenon sometimes is used to justify marginalization and stigmatization of individuals with mental illness, leprosy, physical deformities, and disabilities (Daniel, 1983; Ravindran \& Myers, 2012; Rai, Peters, Syurina, Irwanto, Naniche, \& Zweekhorst, 2020; Wesselmann \& Graziano, 2010). More recently, individuals living with HIV/AIDS have experienced social, cultural, and religious stigmatization (Payán et al., 2017).

Research is limited regarding who is most likely to hold a belief in illness as punishment for sin. In the case of gender, the findings are mixed. A study in India found that women and men are equally likely to believe that God is punishing them for sin with an illness (Bhatnagar et al., 2017). Conversely, a study of differences in gender and culture around beliefs about illness found that women were more likely than men to believe illness was punishment for sin (Klonoff \& Landrine, 1994). One qualitative study found that African American elders with depression believed their illness was a punishment from God rather than having faith in a merciful God (Wittink, Joo, Lewis, \& Barg, 2009). A review of the literature suggested those with higher socioeconomic status were less likely to believe that mental illness was a punishment for $\sin$ (Rabkin, 1972). 


\section{Purpose}

In the current study, we examine the association of demographic and religiosity variables with belief in illness as punishment for sin. Demographic variables included age, gender, education level, and household income. Religiosity variables were comprised of positive religious coping (tendency to use positive religious methods for managing stress), negative religious coping (religious struggle), religious beliefs (beliefs about God) and spiritual health locus of control. Because people facing stressful situations often turn to a higher power for support, religious coping was examined. Positive religious coping involves behaviors such as seeking a stronger connection with God or asking God for forgiveness (Mahamid, \& Bdier, 2021; Pargament, Feuille, \& Burdzy, 2011). Negative religious coping is a form of personal religious struggle (Park, Edmondson, Hale-Smith, \& Blank, 2009; Taylor, Chatters, Woodward, Boddie, \& Peterson, 2021) and is distinct from having a theological belief that illness is a punishment for sin. Religious struggle can be interpersonal (feelings of upset with one's religious community) or intrapersonal (struggles with one's religious beliefs and one's behavior falling short of those beliefs) or can involve a person's perception of the Divine (Damen, et al, 2021; Hill \& Pargament, 2003).

Spiritual health locus of control is a related religious variable comprising perceptions about God's role in one's health-related outcomes (Clark et al, 2017; Holt, Clark, Kreuter, \& Rubio, 2003). Active spiritual health locus of control involves the belief that God empowers the individual to be proactive about health. Passive spiritual health locus of control refers to the belief that God has control over one's health and that personal action is not necessary to be healthy. To our knowledge, the relationship between spiritual health locus of control and the belief in illness as punishment for sin has not been previously investigated.

The purpose of the current study was to examine if belief in illness as punishment was associated with a range of demographic characteristics and aspects of religiosity in African Americans. Because belief in illness as punishment for sin is consistently associated with negative health outcomes (Holt, Lewellyn, \& Rathweg, 2005; Phillips \& Stein, 2007; Reynolds, Mrug, Wolfe, Schwebel, \& Wallander, 2016) and because religious participation is highly valued in the African American community (Thompson, Futterman, \& McDonnell, 2020), we directed our investigation toward correlates of belief in illness as a punishment in African Americans. We focused our investigation on African Americans as they often value religious engagement (Thompson, Futterman, \& McDonnell, 2020), and because African Americans typically carry a greater health burden than European Americans (American Cancer Society, 2019; Centers for Disease Control and Prevention, 2017).

Research Question: What demographic characteristics and religiosity factors predict the belief in illness as punishment for $\sin$ ? 
Hypothesis: The demographic characteristics of education level, employment, and household income, and the religiosity factors of religious beliefs, religious behaviors, positive religious coping, negative religious coping, active spiritual locus of control, and passive spiritual health locus of control will all predict participants endorsing a belief in illness as punishment for sin.

\section{Methods}

\section{Procedure}

The current analyses used data from the Religion and Health in African Americans (RHIAA) study database. The methodology of this study has been reported in more detail elsewhere (Holt, Roth, Clark, \& Debnam, 2014; Schulz et al., 2017). The RHIAA study was an observational cross-sectional study involving telephone interviews in a nation-wide sample of African American adults. The study was approved by the Institutional Review Board (University of Maryland).

\section{Sampling/Study Population}

Eligibility criteria for the study included being 21 years or older and African American without a diagnosis of cancer, due to cancer screening questions included in the survey (Holt, Roth, et al., 2014). One adult who self-identified as African American per household was permitted to participate, and participants received a $\$ 25$ gift card. From a nationwide probability-based sample, 12,418 phone numbers were randomly called by Opinion America, a market research firm; 10,048 individuals were contacted successfully. After excluding the ineligible, 3173 people completed the interview, a $23 \%$ response rate, with 2,172 participants having complete data for the Illness as Punishment for Sin scale. Demographic characteristics of participants are presented in Table 1.

Table 1.

Demographic Characteristics of Study Participants $(N=2,172)$

\begin{tabular}{lr}
\hline Variable & $n(\%)$ \\
\hline Gender & $818(37.7)$ \\
$1=$ Male & $1,354(62.3)$ \\
$2=$ Female & $53.3(14.7)$ \\
Age $(M[\mathrm{SD}])$ & $21-91$ \\
Range & \\
Employment & $845(38.9)$ \\
$1=$ Full-time employed & $254(11.7)$ \\
$2=$ Part-time employed & $265(12.2)$ \\
$3=$ Not currently employed & $551(25.4)$ \\
$4=$ Retired & $247(11.4)$ \\
$5=$ Receiving disability & $10(0.5)$ \\
Refused &
\end{tabular}


Table 1.

Demographic Characteristics of Study Participants $(N=2,172)$

\begin{tabular}{lr}
\hline Variable & $n(\%)$ \\
\hline Education & $58(2.6)$ \\
1=Less than grade 8 & $200(9.2)$ \\
$2=$ Grades 9 through 11 & $708(32.6)$ \\
3=Grade 12 or GED & $639(29.4)$ \\
4=College 1 year to 3 years & $559(25.7)$ \\
$5=$ College 4 years or more & $8(0.4)$ \\
Refused & \\
Household Income & $163(7.5)$ \\
Less than $\$ 5,000$ & $240(11.0)$ \\
$\$ 5,001-\$ 10,000$ & $271(12.5)$ \\
$\$ 10,001-\$ 20,000$ & $249(11.5)$ \\
$\$ 20,001-\$ 30,000$ & $224(10.3)$ \\
$\$ 30,001-\$ 40,000$ & $179(8.2)$ \\
$\$ 40,001-50,000$ & $167(7.7)$ \\
$\$ 50,001-\$ 60,000$ & $412(19.0)$ \\
More than $\$ 60,000$ & $267(12.3)$ \\
Refused &
\end{tabular}

Note. GED = general equivalency diploma.

\section{Data Collection Tools}

Demographic data from the study included items on participant age (What is your age?), gender (What is your gender; $1=$ male, $2=$ female), employment (Do you work for pay outside of the home? $1=$ Full time employed; $2=$ part time employed, $3=$ Not currently employed; $4=$ Retired; $5=$ Receiving disability payments); education level (What is the highest grade or year of school you completed? 1 = Never attended school or only attended kindergarten; $2=$ Grades 1 through $8 ; 3=$ Grades 9 through $11 ; 4=$ Grade 12 or GED; $5=$ College 1 year to 3 years; $6=$ College 4 years or more); and household income (What is the total income of everyone in your household per year, before taxes?).

Belief in Illness as Punishment for Sin was assessed with eight questions on a 4-point Likert scale ( $1=$ strongly disagree, $2=$ disagree, $3=$ agree, $4=$ strongly agree) (Holt et al., 2009). Example items include: "God uses sickness to send a message to people." "Illness comes because of something bad a person has done in their life." "God uses sickness as a way to punish people for their sins." Scores ranged from 8-32, and higher scores indicated higher levels of belief. Internal consistency of the Illness as Punishment for Sin scale was good in the present sample (Cronbach's $\alpha=.89$ ).

Religious involvement was assessed with a 9-item instrument (Lukwago, Kreuter, Bucholtz, Holt, \& Clark, 2001) including items reflecting religious beliefs (e.g., personal relationship with God) and behaviors or participation (e.g., religious service attendance) on a 5-point Likert scale from 1 (strongly disagree) to 5 (strongly agree). 
An example item measuring religious beliefs or personal relationship with God states: "I am often aware of the presence of God in my life". For measuring religious behaviors an example item states: "I often watch or listen to religious programs on TV or radio". Higher scores indicated greater religious involvement. Internal reliability in this sample of the beliefs $(\alpha=.89)$ and behaviors $(\alpha=.73)$ subscales were good and acceptable, respectively.

The Brief Religious Coping Scale (Brief RCOPE) used six items to measure positive and negative religious coping (three items for each) (Pargament, Feuille, \& Burdzy, 2011). An example of an item measuring positive religious coping is, "I work together with God as partners to get through hard times." For negative religious coping, one example item states, "I wonder whether God has abandoned me." Items were rated from 1 (not at all) to 4 (a great deal), and the range was 3-12, where higher scores indicated higher use of each type of religious coping. In the present sample, the reliability for the Brief RCOPE was $\alpha=.75$ for positive religious coping and $\alpha$ $=.52$ for negative religious coping, which was reasonable given the brevity of the subscales according to Nunnally and Bernstein (1994).

The Spiritual Health Locus of Control Scale includes 13 items. Active spiritual health locus of control was measured by 11 items that assessed the belief that God empowers the individual to be proactive about health ( $\alpha=.90$ in the current sample). For example, "Even though I trust God will take care of me, I still need to take care of myself." Passive spiritual health locus of control was measured by two items that assessed the belief that God has control over one's health and that personal action is not necessary ( $r=.59$ in the current sample). For example: "It's ok not to seek medical attention because I feel that God will heal me". Items were rated a 5-point Likert scale from 1 (strongly disagree) to 5 (strongly agree) with higher scores indicating greater levels of the belief.

\section{Statistical Analysis}

Summary statistics were reported using mean (standard deviation [SD]) and count (percentage) as appropriate. Normality assumptions were evaluated using the ShapiroWilk test. Mann-Whitney tests were used to evaluate differences in mean values. Spearman correlation coefficients were used to estimate the strength of the relationship between the Illness as Punishment for Sin scale and religious and psychosocial scale scores. Analyses were conducted using SPSS version 24 (IBM Corp., Armonk, NY). A p-value of .05 (two-tailed) was used for statistical significance. To evaluate the relative contributions of the demographic and the religious predictors, we conducted two linear regression models for demographic and religious variables, respectively, using stepwise entry with entry criteria of .05 and removal criteria of 10. 


\section{Findings}

Illness as Punishment for Sin scale scores were modestly right-skewed, mean (SD) $=$ $16.0(4.59)$ and median $(\mathrm{IQR})=16(13-18)$ out of a possible 32 points. The Shapiro-Wilk test indicated the distribution deviated significantly from normality, $p<.001$. One hundred eighty-three respondents indicated, "strongly disagree" for all eight items (score $=8$ ), and 32 indicated, "strongly agree" for all eight items (score $=32$ ). Therefore, non-parametric Spearman correlations were run to determine if there were significant relationships between belief in illness as punishment for sin and demographic and religiosity factors. The correlations between demographic characteristics and belief in illness as punishment suggested that participants who were younger, male, less educated, had lower income, who were not employed, and held significantly stronger belief in illness as punishment for sin, all of which had small effect sizes. Lower religious beliefs (small effect size), higher negative religious coping (small effect size), and higher passive spiritual health locus of control (medium effect size) were related to higher belief in illness as punishment for sin, while religious behaviors, positive religious coping and active spiritual health locus of control were not significant. Findings for the Spearman correlations are below (see Table 2). Intercorrelations among the predictor variables (Table 2) indicate that some of the demographic variables were associated with the religiosity factors.

Table 2.

Spearman Rho Correlation Matrix for All Variables

\begin{tabular}{|c|c|c|c|c|c|c|c|c|c|c|c|}
\hline Variables & 1 & 2 & 3 & 4 & 5 & 6 & 7 & 8 & 9 & 10 & 11 \\
\hline $\begin{array}{l}\text { Belief in Illness as } \\
\text { Punishment }\end{array}$ & -.00 & $-.06 * *$ & $\underline{-.24 * *}$ & $\underline{-.24 * *}$ & $.11 *$ & $-.10 * * *$ & .03 & .03 & $.29 * * *$ & .07 & $.45 * * *$ \\
\hline 1. Age & 1.00 & .035 & $\underline{-.11 * *}$ & $.49 * *$ & $-.11 * *$ & .01 & $.15 * *$ & $.10 * *$ & $-.06 * *$ & -.010 & $.08 * *$ \\
\hline 2. Gender & & .1 .00 & .00 & .02 & $-.12 * \%$ & $.15 * *$ & $.19 * *$ & $.13 * *$ & $-.16 * *$ & .023 & .023 \\
\hline 3. Education & & & 1.00 & $-.27 * *$ & $.48 * *$ & $.06 * *$ & .03 & .00 & $-.15 * *$ & -.020 & $-.24 * *$ \\
\hline $\begin{array}{l}\text { 4. Household } \\
\text { Income }\end{array}$ & & & & 1.00 & $-.43 * *$ & $-.04 *$ & $.04 *$ & -.02 & $.05 *$ & -.030 & $.13 * *$ \\
\hline 5. Employment & & & & & 1.00 & $.05 *$ & .01 & -.02 & $-.17 * *$ & .01 & $\underline{-.25 * *}$ \\
\hline 6. Religious Beliefs & & & & & & 1.00 & $.52 * *$ & $.37 * *$ & $-.23 * *$ & $.43 * *$ & $-.11 * *$ \\
\hline $\begin{array}{l}\text { 7. Religious } \\
\text { Behaviors }\end{array}$ & & & & & & & 1.00 & $.39 * *$ & $-.18 * *$ & $.29 * *$ & -.00 \\
\hline $\begin{array}{l}\text { 8. Positive } \\
\text { Religious Coping }\end{array}$ & & & & & & & & 1.00 &.$- .17 * *$ & $.28 * *$ & -.00 \\
\hline $\begin{array}{l}\text { 9. Negative } \\
\text { Religious Coping }\end{array}$ & & & & & & & & & 1.00 & -.04 & $.10 * *$ \\
\hline $\begin{array}{l}\text { 10. Active Spiritual } \\
\text { Health Locus of } \\
\text { Control }\end{array}$ & & & & & & & & & & 1.00 & $\underline{-.12 * *}$ \\
\hline $\begin{array}{l}\text { 11. Passive } \\
\text { Spiritual Health } \\
\text { Locus of Control }\end{array}$ & & & & & & & & & & & 1.00 \\
\hline $\begin{array}{l}\mathrm{N}=3,173 \\
* \text {. Correlation is sign } \\
* * \text {. Correlation is sig } \\
* * * \text {. Correlation is si }\end{array}$ & can & the & lev & tai & 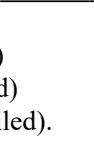 & & & & & & \\
\hline
\end{tabular}


For the binary demographic variable of gender, t-tests were also conducted. There was a significant difference $(t=2.34 ; p=.020)$ between the genders with males $(M=16.29, S D=4.65)$ reporting a stronger belief in illness as punishment for sin than females $(M=15.82, S D=4.55)$.

To evaluate the relative contributions of the demographic and the religious predictors, we conducted a linear regression analysis using stepwise entry with entry criteria of .05 and removal criteria of 10 . The linear regression model combining both demographic characteristics and religiosity factors was significant, $R^{2}=.27$, adjusted $R^{2}=.26, F$ $(12,1834)=55.95, p<.001$. It also indicated that male participants, those who were less educated, those with lower income levels, with lower religious beliefs, greater religious behaviors, greater use of negative religious coping, and both active and passive spiritual health locus of control beliefs, reported significantly stronger belief in illness as punishment for sin. Age, employment, and positive religious coping were not significant (See Table 3 for linear regression analysis).

Table 3.

Linear regression with demographic characteristics and religiosity predicting belief in illness as punishment for sin.

\begin{tabular}{|c|c|c|c|c|}
\hline Independent Variable & B & SEB & Beta & $\mathbf{p}$ \\
\hline Age & -.01 & .01 & -.04 & .09 \\
\hline Gender & -.38 & .20 & -.04 & $\underline{.05}$ \\
\hline Education & -.21 & .11 & -.05 & .049 \\
\hline Household Income & -.14 & .05 & -.07 & .006 \\
\hline Employment & .01 & .08 & .01 & .95 \\
\hline Religious Beliefs & -.12 & .05 & -.07 & .009 \\
\hline Religious Behaviors & .10 & .03 & .08 & .002 \\
\hline Positive Religious Coping & -.02 & .05 & -.01 & .68 \\
\hline Negative Religious Coping & .52 & .06 & .20 & .001 \\
\hline Active Spiritual Health Locus of Control & .10 & .02 & .17 & .001 \\
\hline Passive Spiritual Health Locus of Control & .93 & .06 & .34 & .001 \\
\hline
\end{tabular}

$\mathrm{N}=1847$

$B=$ unstandardized regression coefficient; $S E B=$ standard error of the unstandardized regression coefficient; Beta $=$ standardized regression coefficient; $P=$ Probability value

\section{Discussion}

The current study examined the prevalence of the belief in illness as a punishment for sin in a national probability sample of African American adults and examined how these beliefs were related to demographic characteristics and religiosity factors. Our findings suggested that belief in illness as punishment for sin was moderately endorsed by participants and related to several participant characteristics. Four of the 6 demographic predictors were significantly related: gender, education, employment, and income. Of these, having a lower income had the strongest relationship with belief in illness as punishment for sin. Age was not significantly associated with belief in illness as punishment for sin. 
Regarding religiosity factors, our correlation findings demonstrated that 3 of the 6 variables were significantly related to endorsing a belief in illness as punishment for sin: religious beliefs, negative religious coping, and passive spiritual health locus of control. Lower religious beliefs, higher negative religious coping, and higher passive spiritual health locus of control were related to higher belief in illness as punishment for sin. Of these religiosity factors, passive spiritual health locus of control had the strongest relationship with belief in illness as punishment for sin. Religious behaviors, positive religious coping and active spiritual health locus of control were not significantly correlated with belief in illness as punishment for sin.

Our finding that men are more likely than women to believe in illness as punishment for sin was unexpected. These findings contradict Klonoff and Landrine (1994), who found in a study of Whites and ethnic minority (African Americans, Mexican Americans, and Asian Americans) college students that women were more likely to endorse this belief than men, regardless of race or ethnicity. Perhaps this difference is due to the difference in samples, for example, persons in college vs. not in college.

Our finding that age was not significantly associated with illness as punishment for sin was also surprising. One study found that African American elders with depression believed their illness was a punishment from God instead of believing in a God of mercy (Mills et al, 2017). The authors used a different method for data collection (i.e., semi-structured interviews) than used in the current study, which may account for the finding. Also, their sample was limited to those who were depressed or elders. Since scant literature about demographic factors and the belief in illness as punishment for sin exists, additional studies are necessary to examine this belief in all age groups, particularly adults, in African American and other racial groups (Mills et al, 2017).

Regarding education level and household income, our findings also suggested that those with less education and lower income were more likely to believe in illness as punishment for sin. These findings are consistent with other literature (Rabkin, 1972). It is possible the lower SES and education association with belief in illness as punishment for sin might simply be because, as the literature suggests, people in those categories are generally higher in religiosity factors which may reinforce such a belief (Brandt, \& Henry, 2012; Schieman, Nguyen, \& Elliott, 2003).

Our correlational findings suggested that the religiosity factors of lower religious beliefs, higher negative religious coping, and higher passive spiritual health locus of control were significantly associated with endorsing a belief in illness as punishment for sin. Since the belief in illness as punishment for sin is not empowering to those who believe in it, these significant associations make intuitive sense. These findings suggest that psychologists, healthcare providers and clergy who serve those with 
health challenges should discuss these beliefs and encourage health-enhancing behaviors, particularly in the African American population.

From our linear regression model, we found several significant predictors among both the demographic characteristics and the religiosity factors. Gender, education, and income were significant demographic predictors, while age and employment were not significant predictors. Men, lower education participants, and lower income participants reported higher beliefs in illness as punishment from God. For the religiosity factors, lower religious beliefs, higher religious behaviors, higher negative religious coping, higher passive spiritual health locus of control and higher active spiritual health locus of control were found to be predictors, while positive religious coping was not found to be a predictor of belief in illness as punishment for sin. The 3 variables with the strongest relationship to belief in illness as punishment for sin in descending order were: passive spiritual health locus of control, followed by negative religious coping, followed by gender. Interestingly, the regression analysis found that higher religious behaviors were related to higher belief in illness as punishment, but this was not the case in our correlational results in which religious behaviors were not significantly correlated with illness as punishment beliefs. This suggests that religious behaviors uniquely predict illness as punishment beliefs when other variables are considered in the regression equation. Also, the relatively high correlation between religious beliefs and religious behaviors ( $r=0.52$; Table 2$)$ may explain why higher religious behaviors but lower religious beliefs predict illness as punishments beliefs in the regression analyses since regression indicates the unique contribution of each variable.

We found higher negative religious coping or personal religious struggle - but not positive religious coping - was correlated with the higher belief in illness as punishment for sin. Negative religious coping predicted and mediated increased alcohol consumption in previous studies (Brewer et al., 2015; Holt, Clark, et al., 2014). The current study also found that having lower religious beliefs was associated with stronger belief in illness as punishment for sin, which is interesting given the previously reported correlation between belief in illness as punishment for sin and lower SES and education. It is unknown whether this is because participants held a negative religious belief in illness as punishment for sin, which led people to have lower religious beliefs overall, or whether those who had stronger religious beliefs overall were less likely to hold such a negative religious belief. Since the belief in illness as punishment for $\sin$ is associated with negative health outcomes in the extant literature (Phillips \& Stein, 2007; Reynolds et al., 2016) and in many cases religiosity is associated with positive health outcomes (Ellison \& Levin, 1998; Holt et al., 2005), our negative association makes intuitive sense. Our findings also indicated that higher passive spiritual health locus of control was predictive of the belief in illness as punishment for sin. This result may be because passive spiritual health locus of 
control is correlated with negative health behaviors which can lead to the experience of worse health (Clark et al., 2018; Debnam et al., 2012).

An unexpected finding of our study was that active spiritual health locus of control positively predicted the belief in illness as punishment for sin. This finding indicates a complex relationship between the constructs of spiritual health locus of control and belief in illness as punishment for sin. Perhaps some people are more motivated to take responsibility for their health because they believe in illness as punishment for sin and want to avoid said punishment (Kapoor, Harris, \& Baker, 2018). Literature suggests that both active and passive spiritual health locus of control are positively associated with religious beliefs (Clark, Williams, Huang, Roth, \& Holt, 2018; Holt, Lukwago, \& Kreuter, 2003).

Findings of the current study suggested that the belief in illness as punishment for sin can be predicted by several demographic characteristics and religiosity factors correlated with negative health outcomes. Holding a negative belief, such as illness as punishment for sin, can lead to painful feelings of stigmatization for oneself and others (Bhatnagar et al., 2017; Hulett et al., 2018; Lee et al., 2017; Selman et al., 2018). Our results are counter to the intentions of religious institutions that seek to provide solace and comfort to their congregations (Subramaniam, Camacho, Carolan, \& López-Zerón, 2017). Belief in illness as punishment for sin can reinforce shame and guilt from illness and interfere with the benefits of religious consolation (Satterly, 2001). Religious organizations, clinical psychologists and health professionals should consider using these findings to reduce negative health outcomes, as appropriate, while taking into account client contextual factors and respecting their religious beliefs (Ai et al., 2002).

Additional research should compare the relationship between the belief in illness as punishment for sin and demographics between African Americans and other racial groups. Since we found that men were more likely to hold the belief of illness as punishment for sin than women, additional research examining demographic characteristics of African American males relative to this belief is suggested. Further research also is needed to investigate belief in illness as punishment and engagement in risky health behaviors such as alcohol consumption (O'Malley \& Johnston, 2002). Further research is indicated as well to tease out the connections between SES, education level, religious beliefs, and belief in illness as punishment for sin. Finally, additional research is recommended to determine how health outcomes are mediated or moderated by belief in illness as punishment for sin.

Belief in illness as punishment for sin is a teaching affirmed in several religious traditions, and this belief can have positive and negative effects, and be influenced by contextual factors. For example, some individuals may benefit psychologically and spiritually from illness, by perceiving illness as the consequence of wrongdoing in their phenomenological world, whereas others may not attribute illness to human 
transgression. Psychologists, counselors, and other health professionals working with African Americans may be able to use the findings of this study to help their clients develop positive ways of reframing their illnesses if doing so does not interfere with the clients' held religious beliefs or spiritual growth. Counseling and clinical psychology practitioners should collaborate with clergy to address the issue of belief in illness as punishment for $\sin$ in an appropriate way with their religious clients.

\section{Limitations}

The current study had several limitations. The Brief RCOPE Negative Religious Coping construct had a reliability of $\alpha=.52$, which could indicate that the measure is unsound. However, according to Nunnally and Bernstein (1994), this reliability score was reasonable given the brevity of the subscales. Our results were based on selfreported data, which may be subject to recall bias or socially desirable responding. Further, the response rate was $23 \%$, so results may not be representative of a general population of African Americans. However, this study used a national probabilitybased sample and percentages in our sample in terms of region are similar to national statistics, and the response rate is similar to large studies. Because the original study used telephone interviewing (Holt, Roth, et al., 2014), data may have been biased because only people who had land lines were able to participate. Additionally, there may have been a self-selection bias, where religious or spiritual people were more likely to participate. Many of the effect sizes were small, suggesting that there was a small relationship between the demographic and religiosity variables correlating with belief illness as punishment for $\sin$.

\section{Conclusion}

Results of the current study suggested that African American adults hold a moderately strong belief in illness as punishment for sin and that belief is associated with several demographic and religiosity factors. Since that belief and many of the religiosity factors associated with it are also associated with negative health outcomes, those holding said belief may be at risk for poorer health. We acknowledge that faith traditions have good reasons for reinforcing the importance of wholesome behavior in their followers, and that illness may be used by a Higher Power to discipline, refine, or test believers in some circumstances (see, for example, the story of Job from the Biblical and Quranic texts) (Fehige, 2019). The scientific method cannot disprove (or prove) the existence of a higher metaphysical reality. Future research examining the positive and negative effects of beliefs about the etiology of illness may be useful to support better health outcomes in African Americans adults, while doing so in an appropriate, client-centered fashion, respectful of their contexts and held religious beliefs. 


\section{Acknowledgements}

The authors of this paper would like to acknowledge the work of Tina Madison and Opinion-America who conducted participant recruitment/retention and data collection activities for this research.

The first author would like to thank Celia. H. Schulz, PhD, OTR for initially inspiring the theme of this manuscript.

This research was supported by a grant from the Duke University Center for Spirituality, Theology, and Health, through the John Templeton Foundation (\#11993) and grants from the National Cancer Institute, (\#1 R01 CA 105202; \#1 R01 CA154419). The study received approval from the University of Maryland Institutional Review Board (\#373528-1).

The authors have no disclosures to report.

\section{References}

Abulhul, Z. (2020). Treatment of individuals with disabilities throughout history and across religions in Libya. Open Journal of Social Sciences, 8(11), 207-218. https://doi.org/10.4236/ jss.2020.811019

Ai, A. L., Peterson, C., Bolling, S. F., \& Koenig, H. (2002). Private prayer and optimism in middleaged and older patients awaiting cardiac surgery. Gerontologist, 42(1), 70-81. https://doi. org/10.1093/geront/42.1.70

Anandarajah, G., Roseman, J., Mennillo, L. G., \& Kelley, B. (2021). Spirituality in primary palliative care and

beyond: A 20-year longitudinal qualitative study of interacting factors impacting physicians' spiritual care provision over time. Journal of Pain and Symptom Management. https://doi. org/10.1016/j.jpainsymman.2021.05.013

American Cancer Society (2019). Cancer Facts \& Figures for African Americans 2019-2021. Atlanta, GA:

American Cancer Society. Retrieved From: https://www.cancer.org/content/dam/cancer-org/ research/cancer-facts-and-statistics/cancer-facts-and-figures-for-african-americans/cancerfacts-and-figures-for-african-americans-2019-2021.pdf

Anderson, N. L., Andrews, M., Bent, K. N., Douglas, M. K., Elhammoumi, C. V., Keenan, C., ... \& Mattson, $\mathrm{S}$.

(2010). Chapter 5: Culturally based health and illness beliefs and practices across the life span. Journal of Transcultural Nursing, 21(4 suppl 1), 152S-235S. https://doi.org/10.1177/1043659610381094

Avent Harris, J. R., Wahesh, E., Barrow, M., \& Fripp, J. A. (2021). Demographics, Stigma, and Religious Coping and Christian African Americans' Help Seeking. Counseling and Values, 66(1), 73-91. https://doi.org/10.1002/cvj.12145

Bhatnagar, S., Gielen, J., Satija, A., Singh, S. P., Noble, S., \& Chaturvedi, S. K. (2017). Signs of spiritual distress and its implications for practice in Indian palliative care. Indian Journal of Palliative Care, 23, 306-311. https://doi.org/10.4103/IJPC.IJPC_24_17 
Blocker, D. E., Romocki, L. S., Thomas, K. B., Jones, B. L., Jackson, E. J., Reid, L., \&

Campbell, M. K. (2006). Knowledge, beliefs and barriers associated with prostate cancer prevention and screening behaviors among African-American men. Journal of the National Medical Association, 98(8), 1286-1295. Retrieved from https://www.ncbi.nlm.nih.gov/pmc/articles/ PMC2569547/pdf/jnma00195-0048.pdf

Brandt, M. J., \& Henry, P. J. (2012). Psychological defensiveness as a mechanism explaining the relationship

between low socioeconomic status and religiosity. International Journal for the Psychology of Religion, 22(4), 321-332. https://doi.org/10.1080/10508619.2011.646565

Brewer, G., Robinson, S., Sumra, A., Tatsi, E., \& Gire, N. (2015). The influence of religious coping and religious social support on health behaviour, health status and health attitudes in a British Christian sample. Journal of Religion and Health, 54, 2225-2234. https://doi.org/10.1007/ s10943-014-9966-4

Centers for Disease Control and Prevention. (2017). African American health: Creating equal opportunities for health. Vital Signs. Retrieved from https:/www.cdc.gov/vitalsigns/aahealth/ index.html

Clark, E. M., Huang, J., Roth, D. L., Schulz, E., Williams, B. R., \& Holt, C. L. (2017). The relationship between religious beliefs and behaviours and changes in Spiritual Health Locus of Control over time in a national sample of African-Americans. Mental Health, Religion \& Culture, 20(5), 449-463. https://doi.org/10.1080/13674676.2017.1356274.

Clark, E. M., Williams, B. R., Huang, J., Roth, D. L., \& Holt, C. L. (2018). A longitudinal study of religiosity, spiritual health locus of control, and health behaviors in a national sample of African Americans. Journal of Religion and Health, 57, 2258-2278. https://doi.org/10.1007/ s10943-017-0548-0

Damen, A., Exline, J., Pargament, K., Yao, Y., Chochinov, H., Emanuel, L., ... \& Fitchett, G. (2021). Prevalence, predictors and correlates of religious and spiritual struggles in palliative cancer patients. Journal of Pain and Symptom Management. https://doi.org/10.1016/j. jpainsymman.2021.04.024

Daniel, S. B. (1983). The tool box approach of the Tamil to the issues of moral responsibility and human destiny. In C. F. Keyes \& E. V. Daniel (Eds.), Karma: An anthropological inquiry (pp. 27-62). Berkeley, CA: University of California Press.

Debnam, K. J., Holt, C. L., Clark, E. M., Roth, D. L., Foushee, H. R., Crowther, M., ... Southward, P. L. (2012). Spiritual health locus of control and health behaviors in African Americans. American Journal of Health Behavior, 36, 360-372. https://doi.org/10.5993/AJHB.36.3.7

Durham, C., \& Ramcharan, P. (2018). Insight into acquired brain injury: Factors for feeling and faring better. Singapore: Springer, pp. 31-51.

Ellison, C. G., \& Levin, J. S. (1998). The religion-health connection: Evidence, theory, and future directions. Health Education \& Behavior, 25(6), 700-720. https://doi. org/10.1177/109019819802500603

Emlet, C. A., Harris, L., Pierpaoli, C. M., \& Furlotte, C. (2018). “The journey I have been through”: The role of religion and spirituality in aging well among HIV-positive older adults. Research on Aging, 40, 257-280. https://doi.org/10.1177/0164027517697115

Fehige, Y. (2019). The Book of Job as a thought experiment: On science, religion, and literature. Religions, 10(2), 77. https://doi.org/10.3390/rel10020077 
Hagger, M. S., \& Orbell, S. (2021). The common sense model of illness self-regulation: A conceptual review and proposed extended model. Health Psychology Review, 1-31. https://doi.org/10.1080 $/ 17437199.2021 .1878050$

Holt, C. L., Clark, E. M., Debnam K. J., \& Roth, D. L. (2014). Religion and health in African Americans: The role of religious coping. American Journal of Health Behavior, 38, 190-199. https://doi.org/10.5993/AJHB.38.2.4

Holt, C. L., Clark, E. M., Kreuter, M. W., \& Rubio, D. M. (2003). Spiritual health locus of control and breast cancer beliefs among urban African American women. Health Psychology, 22, 294299. https://doi.org/10.1037/0278-6133.22.3.294

Holt, C. L., Clark, E. M., \& Roth, D. L. (2014). Positive and negative religious beliefs explaining the religion-health connection among African Americans. The International Journal for the Psychology of Religion, 24(4), 311-331. https://doi.org/10.1080/10508619.2013.828993

Holt, C. L., Clark, E. M., Roth, D., Crowther, M., Kohler, C., Fouad, M., ... Southward, P. L. (2009). Development and validation of instruments to assess potential religion-health mechanisms in an African American population. Journal of Black Psychology, 35(2), 271-288. https://doi. org/10.1177/0095798409333593

Holt, C. L., Lewellyn, L. A., \& Rathweg, M. J. (2005). Exploring religion-health mediators among African American parishioners. Journal of Health Psychology, 10(4), 511-527. https://doi. org/10.1177/1359105305053416

Holt, C. L., Lukwago, S. N., \& Kreuter, M. W. (2003). Spirituality, breast cancer beliefs and mammography utilization among urban African American women. Journal of Health Psychology, 8(3), 383-396.

Holt, C. L., Roth, D. L., Clark, E. M., \& Debnam, K. (2014). Positive self-perceptions as a mediator of religious involvement and health behaviors in a national sample of African Americans. Journal of Behavioral Medicine, 37, 102-112. https://doi.org/10.1007/s10865-012-9472-7

Hulett, J. M., Armer, J. M., Leary, E., Stewart, B. R., McDaniel, R., Smith, K., ... Millspaugh, J. (2018). Religiousness, spirituality, and salivary cortisol in breast cancer survivorship: A pilot study. Cancer Nursing, 41, 166-175. https://doi.org/10.1097/NCC.0000000000000471

Kapoor, A., Harris, S. T., \& Baker, E. A. (2018). Fear vs. faith: How a 46 year old woman beat breast cancer. Spiritual Care, 7, 191-196. https://doi.org/10.1515/spircare-2017-0037

Klonoff, E. A., \& Landrine, H. (1994). Culture and gender diversity in commonsense beliefs about the causes of six illnesses. Journal of Behavioral Medicine, 17(4), 407-418. https://doi. org/10.1007/bf01858011

Koenig, H. G., King, D. E., \& Carson, V. B. (2012). Handbook of religion and health (2nd ed.).

New York, NY: Oxford University Press.

Lee, J. A., Nguyen, H., Park, J., Tran, L., Nguyen, T., \& Huynh, Y. (2017). Usages of computers and smartphones to develop dementia care education program for Asian American family caregivers. Healthcare Informatics Research, 23, 338-342. https://doi.org/10.4258/ hir.2017.23.4.338

Lukwago, S. N., Kreuter, M. W., Bucholtz, D. C., , C. L., \& Clark, E. M. (2001). Development and validation of brief scales to measure collectivism, religiosity, racial pride, and time orientation in urban African American women. Family and Community Health, 24(3), 63-71. https://doi. org/10.1097/00003727-200110000-00008 
Mahamid, F. A., \& Bdier, D. (2021). The association between positive religious coping, perceived stress, and depressive symptoms during the spread of coronavirus (Covid-19) among a sample of adults in Palestine: A cross sectional study. Journal of Religion and Health, 60(1), 34-49.

Masci, D. (2018, February 7). 5 facts about the religious lives of African Americans. Pew Research Center. Retrieved from http://www.pewresearch.org/fact-tank/2018/02/07/5-facts-about-thereligious-lives-of-african-americans/

Mills, S. D., Arredondo, E. M., Perez, L. G., Haughton, J., Roesch, S. C., \& Malcarne, V. L. (2017). Psychometric Evaluation of the Spanish versions of the Perceived Religious Influence on Health Behavior scale and the Illness as Punishment for Sin scale in a Sample of Churchgoing Latinas. The International Journal for the Psychology of Religion, 27(4), 188-198. https://doi.or g/10.1080/10508619.2017.1378973

Newport, F. (2016, June 29). Most Americans still believe in God. Gallup. Retrieved from https:// news.gallup.com/poll/193271/americans-believe-god.aspx

Nunnally, J. C., \& Bernstein, I. H. (1994). Psychometric Theory (McGraw-Hill Series in Psychology) (Vol. 3). New York: McGraw-Hill.

O’Malley, P. M., \& Johnston, L. D. (2002). Epidemiology of alcohol and other drug use among American college students. Journal of Studies on Alcohol, Supplement, (14), 23-39. https://doi. org/10.15288/jsas.2002.s14.23

Pargament, K., Feuille, M., \& Burdzy, D. (2011). The Brief RCOPE: Current psychometric status of a short measure of religious coping. Religions, 2, 51-76. https://doi.org/10.3390/rel2010051

Park, C. L., Edmondson, D., Hale-Smith, A., \& Blank, T. O. (2009). Religiousness/spirituality and health behaviors in younger adult cancer survivors: Does faith promote a healthier lifestyle? Journal of Behavioral Medicine, 32, 582-591. https://doi.org/10.1007/s10865-009-9223-6

Payán, D. D., Flórez, K. R., Bogart, L. M., Kanouse, D. E., Mata, M. A., Oden, C. W., \& Derose, K. P. (2017). Promoting health from the pulpit: A process evaluation of HIV sermons to reduce HIV stigma and promote testing in African American and Latino churches. Health Communication. Advance online publication. https://doi.org/10.1080/10410236.2017.1384352

Phillips, R. E., \& Stein, C. H. (2007). God's will, God's punishment, or God's limitations? Religious coping strategies reported by young adults living with serious mental illness. Journal of Clinical Psychology, 63(6), 529-540.

Rabkin, J. G. (1972). Opinions about mental illness: A review of the literature. Psychological Bulletin, 77(3), 153-171. https://doi.org/10.1037/h0032341

Rai, S. S., Peters, R. M., Syurina, E. V., Irwanto, I., Naniche, D., \& Zweekhorst, M. B. (2020). Intersectionality and

health-related stigma: Insights from experiences of people living with stigmatized health conditions in Indonesia. International Journal for Equity in Health, 19(1), 1-15. https://doi.org/10.1186/ s12939-020-01318-w

Ransome,Y.(2020). Religion, spirituality, and health:New considerations for epidemiology.American Journal of

Epidemiology, 189(8), 755-758. https://doi.org/10.1093/aje/kwaa022

Ravindran, N., \& Myers, B. J. (2012). Cultural influences on perceptions of health, illness, and disability: A review and focus on autism. Journal of Child and Family Studies, 21(2), 311-319. https://doi.org/10.1007/s10826-011-9477-9 
Retief, M., \& Letšosa, R. (2018). Models of disability: A brief overview. HTS Teologiese Studies/ Theological Studies, 74, a4738. https://doi.org/10.4102/hts.v74i1.4738

Reynolds, N., Mrug, S., Wolfe, K., Schwebel, D., \& Wallander, J. (2016). Spiritual coping, psychosocial adjustment, and physical health in youth with chronic illness: A meta-analytic review. Health Psychology Review, 10, 226-243. https://doi.org/10.1080/17437199.2016.1159142

Satterly, L. (2001). Guilt, shame, and religious and spiritual pain. Holistic Nursing Practice, 15(2), 30-39. https://doi.org/10.1097/00004650-200101000-00006

Schieman, S., Nguyen, K., \& Elliott, D. (2003). Religiosity, socioeconomic status, and the sense of mastery. Social Psychology Quarterly, 202-221. https://doi.org/https://doi.org/10.2307/1519822

Schulz, E., Bay, R. C., Williams, B. R., Clark, E.M., Huang, J., \& Holt, C. L. (2017). Fruit and vegetable consumption, and physical activity with partner and parental status in African American adults. Journal of Family Medicine and Community Health, 4(4), 1115. https://www. ncbi.nlm.nih.gov/pmc/articles/PMC5891144/pdf/nihms893603.pdf

Selman, L. E., Brighton, L. J., Sinclair, S., Karvinen, I., Egan, R., Speck, P., ... InSpirit Collaborative. (2018). Patients' and caregivers' needs, experiences, preferences and research priorities in spiritual care: A focus group study across nine countries. Palliative Medicine, 32, 216-230. https://doi.org/10.1177/0269216317734954

Shiri, F. H., Mohtashami, J., Manoochehri, H., Nasiri, M., \& Rohani, C. (2020). Care Plan for Reducing Stigma in Cancer Disease. Open Journal of Nursing, 10(11), 1142-1154. https://doi. org/10.4236/ojn.2020.1011081

Siler, S., Arora, K., Doyon, K., \& Fischer, S. M. (2021). Spirituality and the illness experience: perspectives of

African American older adults. American Journal of Hospice and Palliative Medicine, 38(6), 618625. https://doi.org/10.1177/1049909120988280

Stainton, T. (2008). Reason, grace and charity: Augustine and the impact of church doctrine on the construction of intellectual disability. Disability \& Society, 23(5), 485-496. https://doi. org/10.1080/09687590802177056

Stanford, M. S. (2007). Demon or disorder: A survey of attitudes toward mental illness in the Christian church. Mental Health, Religion \& Culture, 10(5), 445-449. https://doi. org/10.1080/13674670600903049

Subramaniam, S., Camacho, L. M., Carolan, M. T., \& López-Zerón, G. (2017). Resilience in lowincome African American women living and aging with HIV. Journal of Women \& Aging, 29, 543-550. https://doi.org/10.1080/08952841.2016.1256735

Taylor, R. J., Chatters, L., Woodward, A. T., Boddie, S., \& Peterson, G. L. (2021). African Americans' and Black Caribbeans' religious coping for psychiatric disorders. Social Work in Public Health, 36(1), 68-83. https://doi.org/10.1080/19371918.2020.1856749

Thompson, E. H., Futterman, A. M., \& McDonnell, M. O. (2020). The legacy of the Black Church: older African Americans' religiousness. Journal of Religion, Spirituality \& Aging, 32(3), 247267. https://doi.org/10.1080/15528030.2019.1611521

Wesselmann, E. D., \& Graziano, W. G. (2010). Sinful and/or possessed? Religious beliefs and mental illness stigma. Journal of Social and Clinical Psychology, 29(4), 402-437. https://doi. org/10.1521/jscp.2010.29.4.402

Wittink, M. N., Joo, J. H., Lewis, L. M., \& Barg, F. K. (2009). Losing faith and using faith: Older African Americans discuss spirituality, religious activities, and depression. Journal of General Internal Medicine, 24, 402-407. https://doi.org/10.1007/s11606-008-0897-1 
